\title{
Microscopic assessment of healing and effectiveness of foam-based peripheral occlusion device
}

Staci L. Jessen ${ }^{1,2}$, Molly C. Friedemann ${ }^{1}$, Anne-Marie Ginn-Hedman², Lance M. Graul ${ }^{2}$, Steven

Jokerst $^{2}$, Cedric B. Robinson ${ }^{1}$, Todd L. Landsman ${ }^{3}$, Fred J. Clubb, Jr. ${ }^{1,2}$, Duncan J. Maitland ${ }^{2,3, *}$

${ }^{1}$ Department of Veterinary Pathobiology, Texas A\&M University, College Station, TX

${ }^{2}$ Department of Biomedical Engineering, Texas A\&M University, College Station, TX

${ }^{3}$ Shape Memory Medical Inc., Santa Clara, CA

\section{SUPPLEMENTARY INFORMATION}

Total Number of Supplementary Pages: 1

Total Number of Supplementary Tables: 1

Total Number of Supplementary Figures: 0 


\section{Table S1. Percentages of Cell Types Within Central, Mid, and Outer Regions of Histology Slides at 30, 60, and 90 Day Time Points}

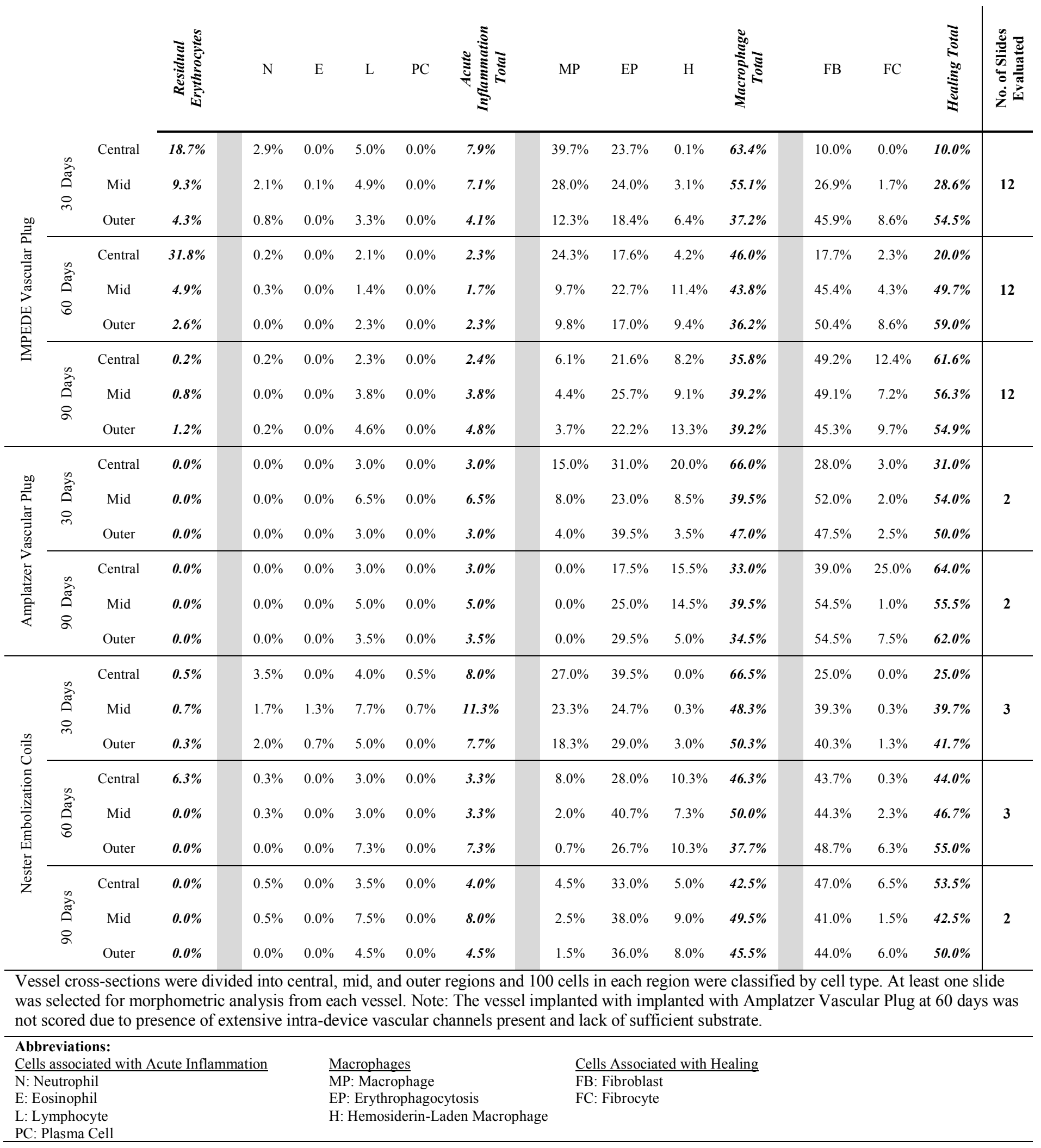

